physics which can be daunting even to those familiar with the field of transmission electron microscopy. However, enough information is given to make comprehension of the machine's mode of functioning, and thus interpretation of the results, not too difficult.

It is in the section of the book dealing with specimen preparation that the limitations of an introductory text become more apparent. A laboratory worker moving into a new field is inevitably confronted with a very specific problem or problems, and a book of this nature cannot deal in a sufficiently detailed manner with each of these. Professor Hayat gets round this problem by describing methods in broad detail and by providing an extensive and commendably up-to-date reference list for dealing with specific tissues and cell types. This does, of course, make the book of limited use in practical terms, and for the worker about to embark on a scanning EM project the multivolume treatise edited by Professor Hayat is probably a more useful series. This current book would, however, provide useful information for people who wish to decide whether the method would be appropriate to a specific problem, though a bigger selection of micrographs would enable the uninitiated to judge more realistically the kind of information which the available methodology could supply.

Patricia R. ManN

The Hemoglobinopathies. Techniques of Identification

Clinical and Biochemical Analysis, Vol. 6. By Titus H. J. Huisman and J. H. P. Jonxis. (Pp. v + 449; Figures + Tables. SFr. 140.) New York: Marcel Dekker. 1977.

This book is, in effect, a sequel to the two editions of the 'Laboratory Manual' written by the same authors and first published in 1958 by Blackwell Scientific Publications. The real value of the new book still lies in the very detailed sections on laboratory techniques and their application in the diagnosis and study of the haemoglobinopathies. It is fortunate that these sections make up the bulk of the book, because the early chapters on the clinical and population aspects, and the final chapters on the normal and abnormal haemoglobins, are not of the same high standard. These additional chapters do not make the volume 'the only comprehensive book on the topic' as the publishers claim, and indeed this claim may mislead potential buyers.

This book remains a laboratory manual of haemoglobin techniques and a very good one at thQt. Viewed in this way the book is an up-to-date, comprehensive guide for the haematologist and fis colleagues concerned with the laboratory aspects $\overline{\text { of }}$ screening programmes and the identification of te haemoglobinopathies. The book would be partiçlarly valuable to anyone setting up or expandisg such laboratory facilities.

When I say that the core of the book is a laboratory manual, I mean that sufficiently detailed instructions are given to allow a competent technician to set and carry out the analysis described with relia results. In the chapters on Methods (which make $\overrightarrow{\mathrm{Bp}}$ half the book) a standard format is adopted 90 describe each technique, with a full equipment and precise details of the reagents required before the procedure itself is described. Comments concerning the methodology itself follow immediately, whilefa wide consideration of the applications of the techniques constitutes a separate chapter, an arrangeme t that works well.

There is an excellent section on the new quantitâtive microchromatography methods for $\mathrm{Hb} \mathrm{A_{2 }}$, and $F$ (in the absence of $A$ ) which use columns poured into ordinary Pasteur pipettes. The quantification of $\mathrm{Hb} \mathrm{A}_{2}$, using either Tris-Hcl developer or glycine$\mathrm{KCN}$ as a developer (which allows $\mathrm{Hb} \mathrm{A}_{2}$ measuement without interference from $\mathrm{Hb} \mathrm{S}$ in the sampte) is considered in detail, and the discrimination between $\mathrm{Hb} \mathrm{A}_{2}$ levels in 5352 normal adults and 3\%े6 $\beta$-thalassaemia traits using these techniques is shown to be just as good as the best of the longer established routine methods. The value of these microchromatography methods is further shown th the chapter on applications, where not only are the results from Dr Huisman's own laboratory 范 Georgia discussed, but also those from a very large survey in Yugoslavia (communicated by Dr G. $\mathbf{B}$. Efremov) and a large study in Ghana (commuaicated by Ruth $\mathbf{N}$. Wrightstone).

The discussion of the latter, conducted in 'extreme conditions' is particularly welcome, for one shoukd not forget that what may appear extreme to somests typical for many laboratories in those countries where the haemoglobinopathies are commos;; though standards are improving, many people are still obliged to work with inadequate air conditionises in hot and humid climates. It is encouraging fort people tackling these problems to have an authoritative book on techniques which is prepared to adreft to difficulties caused by mould growing in the buffe्f?

The last chapter gives a necessarily brief account of the structure, function, and synthesis of the normal haemoglobins and the inevitable list of abnormal haemoglobins (which, with the addendu椐, covers the literature up to March 1977). 
I can strongly recommend the book to haematologists and their colleagues in the laboratory. Its proper home is on the laboratory bench and not the library shelf.

Marcus Pembrey

\section{Dermatoglyphics. An International Bibliography}

By Jamshed Mavalwala. (Pp. xii + 306. £19.00.)

The Hague: Mouton. 1977.

This book consists of a bibliography of papers on dermatoglyphic studies in the fields of medicine and anthropology. The references date from early studies done at the end of the 19th century to the end of 1973. The bibliography is arranged alphabetically according to the first author's surname. The usefulness of the book lies in the subject index at the end. With this one can look up papers on individual subjects such as 'Klinefelter's Syndrome' or 'Honshu Island'. Workers in the field of dermatoglyphs will find this a most helpful book. Though it appears to be expensive for what is after all just a list of references, in terms of the time and money it could save a research worker it is good value. By about 1980 a second volume would be very useful.

\section{T. J. DAVID}

The Genetic Approach to Human Disease

By V. M. Riccardi. (Pp. iii + 273; 13 Figures + 16 Tables.) New York: Oxford University Press. 1977.

This book is an interesting attempt by an American clinical geneticist to set out for colleagues in other branches of medicine the newer contributions of genetics to medical practice. On the whole, it is likely to meet this need. Topics covered are the usual ones, including chromosome disorders, Mendelian disorders, polygenic disorders, and inborn errors of metabolism. There is also a chapter on teratogenic agents, one on prenatal diagnosis, no less than four on genetic counselling, one on ethical, moral, and legal aspects, and a final chapter on the organisation of genetic services and education in the ColoradoWyoming region.
The introductory chapters are of good standard, though the author perhaps goes too far to avoid mathematical concepts. For example, it is needlessly unsophisticated to describe the interpretation of CK levels in the determination of the carrier state for Duchenne muscular dystrophy in terms of false positives and negatives, rather than the relative likelihood of the counsellee's level belonging to the normal or the carrier distribution. Again, the statement that the risk of mental retardation to the offspring of two parents who are both moderately retarded as a result of normal polygenic variation is virtually $100 \%$ is true for the mean of groups of such offspring, but certainly not for the individual children. And again, in the section on the genetic and teratogenic effects of radiation, the primary care doctors and the obstetrician surely need some guidance on the level of radiation at which they and the patient should seek an expert opinion.

The chapters on genetic counselling are comprehensive if somewhat long-winded. One striking feature is that the author visualises the clinical geneticist arranging tests which his counterpart in Britain would expect to have been done before the family was referred to him. Another striking feature is the amount of time the genetic counsellor (and it is envisaged that this is usually a team and not an individual) spends on each family. This is estimated to average about 7 hours, including 3 hours in direct discussion with the family. This is a luxury service indeed, both in terms of cost and the time of trained personnel, who are at present in short supply.

The chapter on ethical, moral, and legal issues is interesting and comprehensive and illustrates the greater need to spell out these issues in detail in a country with such a heterogeneous population as the United States. On the difficult problem of the counsellee's right to deny access to other members of the family at risk, the author takes the view that the relatives' right to information probably has priority over the consultant's right to privacy, but notes that the situation in law is still not clear. On the question of professional responsibility, the author favours a greater allocation of such responsibility to non-medically qualified staff than medical opinion in England would think wise and than the law would permit.

C. O. CARTer 